\title{
Enriquecimento de florestas em processo de restauração: aspectos de epífitas e forófitos que podem ser considerados ${ }^{1}$
}

\author{
Marina Melo Duarte ${ }^{2,3}$, Sergius Gandolfi²
}

Recebido: 4.06.2013; aceito: 5.09.2013

\begin{abstract}
Enrichment of forests in process of restoration: aspects of epiphytes and phorophytes that may be considered). Monitoring of forests in process of restoration has shown that they have not been achieving high diversity of life forms. Epiphytes, plants that live on host trees (phorophytes), are essential in an ecosystem. Thus, it is important to promote enrichment of forests using them. The aim of this work is to provide information for procedures of transplantation of epiphytes taken from forests that had to be cut off to areas that have been restored. In order to perform that, we analyzed survival and development of individuals of Aechmea bromeliifolia (Rudge) Baker (Bromeliaceae) a year after been transferred to six distinct host tree species, in a 23-year old Semideciduous Seasonal Forest. These variables did not significantly respond to any particular phorophyte species, bark roughness, or canopy cover. They showed significant differences according to the initial weight of the epiphytes. The middle-sized individuals (105.5 a $239.4 \mathrm{~g}$ ) were the most successful in transplantations. Key words: Aechmea bromeliifolia (Rudge) Baker, Bark roughness, Canopy cover, Epiphyte weight, Restoration Ecology
\end{abstract}

RESUMO - (Enriquecimento de florestas em processo de restauração: aspectos de epífitas e forófitos que podem ser considerados). Pelo monitoramento de florestas em restauração, detectou-se que elas dificilmente atingem alta diversidade de formas de vida. Epífitas, plantas que vivem sobre árvores hospedeiras (forófitos), são fundamentais em um ecossistema. É importante promover o enriquecimento de matas com essa forma de vida. O objetivo deste trabalho é fornecer subsídios teóricos para realizar transplantes de epífitas de florestas que tiveram que ser legalmente desmatadas para florestas em restauração. Para isso, analisou-se a sobrevivência e desenvolvimento de indivíduos de Aechmea bromeliifolia (Rudge) Baker (Bromeliaceae) um ano após terem sido transplantados a seis distintas espécies de forófitos, em Floresta Estacional Semidecidual em restauração há 23 anos. As variáveis analisadas não responderam significativamente de acordo com espécie de forófito, rugosidade de sua casca ou cobertura de dossel. Mostraram diferenças significativas de acordo com o porte das epífitas, de forma que aquelas de massa intermediárias (105,5 a 239,4 g) tiveram maior sucesso no transplante.

Palavras-Chave: Aechmea bromeliifolia (Rudge) Baker, Cobertura de dossel, Ecologia de Restauração, Massa de epífita, Rugosidade de tronco

\section{Introdução}

Epífitas verdadeiras (holoepítas) são plantas que passam todo o seu ciclo de vida sobre hospedeiros (denominados "forófitos") sem, contudo, parasitá-los (Font-Quer 1953). Cerca de $8 \%$ a $10 \%$ das plantas vasculares se comportam como epífitas em alguma fase da vida (Benzing 2004). Seu papel ecológico dentro de um ecossistema é de enorme importância, já que são capazes de fornecer distintos microhabitats e microclimas, abrigando grande diversidade de vida, oferecer recursos como flores, frutos e néctar e, em alguns casos, armazenar, disponibilizar água e umidificar o ambiente do dossel. (Benzing 2004, Cestari 2009). Embora não mantenham contato com o solo, adquirem substâncias essenciais à sobrevivência por diversos meios, retirando-os da precipitação atmosférica, da lixiviação das copas ou mesmo de detritos acumulados. Parte da biomassa que produzem é consumida por animais ou retorna ao solo, contribuindo com a ciclagem de nutrientes, em locais onde são abundantes. (Benzing 2004,

1. Parte de dissertação de Mestrado da primeira Autora, Programa de Recursos Florestais da Escola Superior de Agricultura "Luiz de Queiroz", Universidade de São Paulo

2. Universidade de São Paulo, Escola Superior de Agricultura "Luiz de Queiroz", Laboratório de Ecologia e Restauração Florestal. Av. Pádua Dias 11, 13418-900, Piracicaba, SP, Brasil

3. Autor para correspondência: mmeloduarte@gmail.com 
Nadkarni et al. 2004, Oliveira 2004). Em especial, as bromélias tanque (como $A$. bromeliifolia) têm suas folhas arranjadas formando estrutura capaz de reter água e detritos. Com isso, podem abrigar enorme diversidade de organismos, desde detritívoros a aquáticos, que desempenham distintas funções dentro da cadeia alimentar. Essas plantas, enfim, contribuem com a heterogeneidade ambiental, pela gama de compartimentos e gradientes ecológicos que podem oferecer (Benzing 2004).

Apesar dessa grande importância ecológica em florestas nativas, não é comum que se insiram epífitas em projetos de restauração ecológica. Plantios de restauração, como buscam primeiro a reconstrução de fisionomia florestal, baseiam-se inicialmente apenas em espécies arbóreas de dossel (Carvalhaes et al. 2007, Bellotto et al. 2009). A legislação paulista, pioneira no Brasil no que se refere a normas para a restauração florestal, quando lista espécies recomendadas para o plantio, apenas indica as arbóreas, não mencionando as demais formas de vida (Durigan et al. 2010).

As florestas em restauração, contudo, não vêm recebendo epífitas por meio da dispersão natural, ao longo dos anos. Segundo Garcia et al. (2011), mesmo aquelas consideradas antigas, com cerca de 50 anos, apresentam apenas metade da riqueza das espécies não-arbóreas de ecossistemas de referência. Nadkarni et al. (2004) observaram que florestas secundárias apresentam apenas uma diminuta fração da biomassa de epífitas contida nas primárias. Por outro lado, em certas florestas nativas, epífitas sozinhas podem representar um terço do total de espécies vegetais e mais da metade dos indivíduos (Gentry \& Dodson 1987). A fragmentação da paisagem atual ocasiona o isolamento de populações, dificultando a movimentação de diásporos a longas distâncias e, consequentemente, a colonização de novas áreas pelas epífitas (Cain et al. 2000, Garcia et al. 2011).

Diante da importância fundamental de formas de vida vegetais não arbóreas em uma floresta, sobretudo em paisagens muito fragmentadas, o enriquecimento assistido de áreas em processo de restauração com epífitas vem se mostrando necessário, para que elas venham a adquirir heterogeneidade e processos ecológicos próximos aos de uma mata nativa (Bellotto et al. 2009, Garcia et al. 2011). Uma proposta interessante para isso é a de se retirar epífitas de áreas que serão legalmente desmatadas e transferi-las a florestas em restauração.

No cenário mundial, a taxa de desmatamento é decrescente, porém ainda elevada, tendo sido de 16 milhões de ha ano ${ }^{-1}$ nos anos 1990 e de 13 milhões de ha ano $^{-1}$ nos anos 2000. O Brasil, em 2010, continha $13 \%$ dos aproximadamente 4 bilhões de hectares de floresta do mundo (Food and Agriculture Organization 2011). A Lei $\mathrm{n}^{\circ} 12.651$ de 25 de maio de 2012 delimita as Áreas de Preservação Permanente (APPs) e as Reservas Legais (RLs), áreas dentro de uma propriedade que não devem ser desmatadas. Contudo, dentro de certas condições e limites, áreas que não fazem parte dessas protegidas por lei, e mesmo essas, são passíveis de receber autorizações para supressão vegetal. Tendo em vista que, para permitir certas obras de infraestrutura e de outros interesses gerais, certo grau de desmatamento já é previsto por lei e dificilmente poderá ser evitado, pode-se, ao menos, propor que parte dos indivíduos vegetais existentes nessas áreas (p.ex.: epífitas) seja aproveitada, transferindo-os para o enriquecimento de florestas em restauração.

Alguns trabalhos vêm sendo feitos considerando o transplante de angiospermas epífitas entre florestas (Callaway et al. 2002, Nadkarni \& Solano 2002, Pett-Ridge \& Silver 2002, Zotz \& Vollrath 2002, Jasper et al. 2005, Jakovac et al. 2007, Cascante-Marín et al. 2009, Nievola \& Tamaki 2009, Scheffknetch et al. 2010, Dorneles \& Trevelin 2011). Apenas em uma pequena parte deles, as florestas-alvo estão em processo de restauração ou em diferentes estágios de regeneração (Jakovac et al. 2007, Cascante-Marín et al. 2009). Além disso, a maioria deles tem enfoque não no enriquecimento da mata em questão, mas na conservação das espécies de epífitas escolhidas. No Brasil, apenas recentemente trabalhos voltados à inserção de epífitas em florestas, dentro do contexto da restauração ecológica, vêm sendo feitos (Carvalhaes et al. 2007, Jakovac et al. 2007). Isso porque, no país, a Ecologia de Restauração é uma ciência jovem, com cerca de 30 anos. Ainda há hoje carência de trabalhos para orientar transplantes de epífitas a florestas em processos de restauração. Somente a partir dos anos 2000, quando a avaliação e o monitoramento de florestas em processo de restauração passaram a ser vistos como fundamentais para garantir o sucesso efetivo dos projetos já implantados, é que se tornou evidente a necessidade de enriquecer de maneira sistemática algumas dessas florestas mais antigas que se encontram muito isoladas de fragmentos (Rodrigues et al. 2009).

Nesse contexto, algumas questões referentes à transferência de epífitas podem ser levantadas: a partir de qual idade da floresta em restauração 
a transferência de epífitas pode ser realizada? Há padrões relativos à biologia das epífitas, dos forófitos ou do ambiente que podem aumentar ou diminuir o sucesso dessa transferência? Estudos sobre a biologia de epífitas e sobre a distribuição de suas populações em florestas nativas podem ser úteis para orientar novos transplantes. Eles mostram se há preferência de epífitas por espécies de forófitos (Callaway et al. 2002, Otero et al. 2007, Kersten \& Kuniyoshi 2009, Benavides et al. 2011, Obermüller et al. 2012), pela rugosidade da superfície de seu tronco (Callaway et al. 2002, Addo-Fordjour et al. 2009), por determinadas classes de diâmetro à altura do peito (DAP) (Breier 2005) e por condições ambientais locais (Bonnet et al. 2010). Há certos indícios de que a irradiância possa estar relacionada com a abundância de epífitas em um ponto da floresta (Callaway et al. 2002). Por sua vez, a umidade se mostra um fator de enorme importância à distribuição dessa forma de vida (Gentry \& Dodson 1987, Callaway et al. 2002, Benzing 2004, Breier 2005, Fayle 2009). Nota-se que Jasper et al. (2005) salientaram que a fase de vida em que se encontra a epífita pode influenciar os resultados no transplante.

O presente trabalho é parte de um estudo mais amplo sobre transplantes de epífitas para áreas em restauração, realizado por Duarte (2013). O objetivo, neste trabalho, foi determinar quais fatores exercem influência sobre a sobrevivência e o desenvolvimento de indivíduos da epífita Aechmea bromeliifolia (Rudge) Baker (Bromeliaceae) transplantados para uma Floresta Estacional Semidecidual de 23 anos: tamanho inicial dessas bromélias, rugosidade da casca do forófito e/ou grau de cobertura de dossel.

\section{Material e métodos}

O transplante da espécie de epífita foi realizado em uma Floresta Estacional Semidecidual em processo de restauração há 23 anos, no município de Iracemápolis-SP $\left(22^{\circ} 34^{\prime} 37^{\prime \prime} \mathrm{S}, 47^{\circ} 30^{\prime} 31^{\prime \prime} \mathrm{W}\right)$, a altitude 609 m, de clima Cwa, de acordo com Köppen (Setzer 1966). A pluviosidade anual é de cerca de $1.360 \mathrm{~mm}$ e a temperatura média anual é de $21,5^{\circ} \mathrm{C}$, com médias mensais entre $17,9{ }^{\circ} \mathrm{C}$ e $24,4{ }^{\circ} \mathrm{C}$ (CEPAGRI 2012). A figura 1 mostra índices pluviométricos mensais ao longo do experimento, entre abril de 2011 e abril de 2012. Dados foram obtidos do Posto Agrometeorológico LEB, da Escola Superior de Agricultura "Luiz de Queiroz", Piracicaba-SP, a estação meteorológica mais próxima à área de estudo.

Trata-se de área ao redor de reservatório de água que abastece o município de Iracemápolis-SP. Por volta do ano de 1986, a região enfrentou problemas de falta de água, decorrentes da má conservação da microbacia (Rodrigues et al. 1992). Em 1988, nela foi feito plantio de 140 espécies arbóreas, incluindo nativas de Floresta Estacional Semidecidual e algumas exóticas, para restauração de faixa de $50 \mathrm{~m}$ de área de preservação permanente, previamente ocupada por cana. A área total plantada foi de 50 ha e a densidade variou de 625 a 884 indivíduos ha ${ }^{-1}$, em diferentes pontos. Em recente levantamento florístico e fitossociológico de 2 ha, essa floresta apresentou 143 espécies pertencentes a 40 famílias, com valores médios de dossel de $10 \mathrm{~m}$, de área basal de $25,15 \mathrm{~m}^{2} \mathrm{ha}^{-1}$, de DAP de $11,38 \mathrm{~cm}$ e de densidade

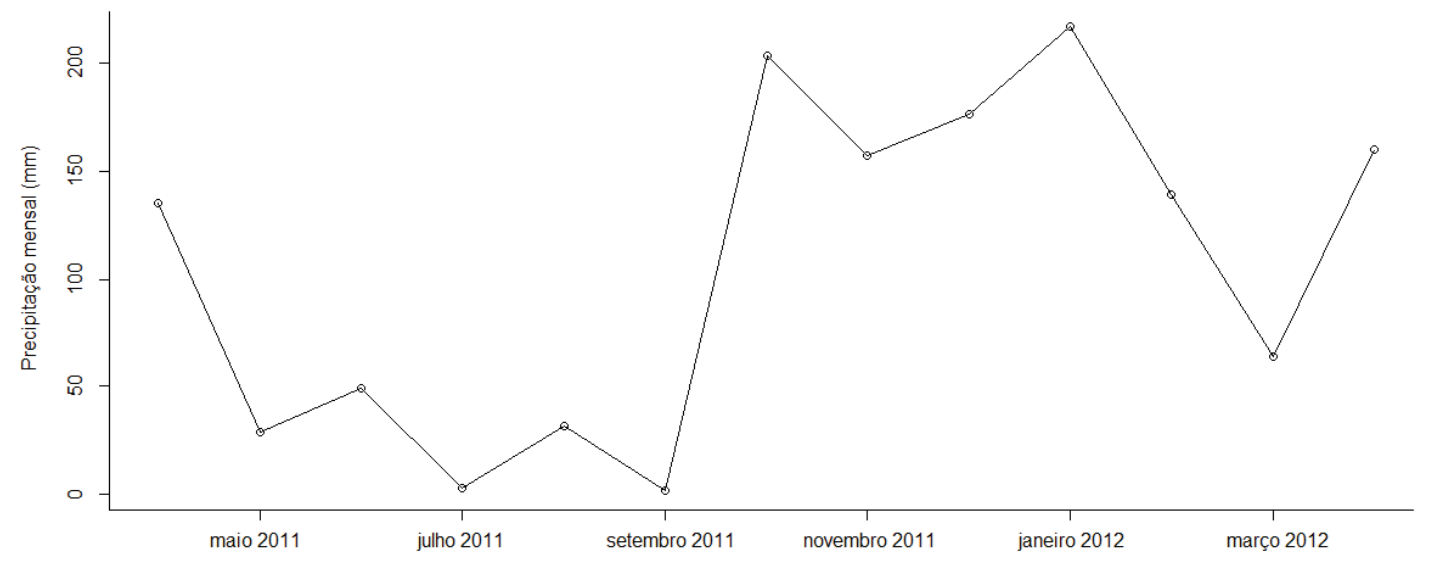

Figura 1. Precipitação mensal (mm) ao longo do experimento, entre abril de 2011 e abril de 2012. Dados obtidos no Posto Agrometeorológico LEB, da Escola Superior de Agricultura "Luiz de Queiroz", Piracicaba, SP, Brasil.

Figure 1: Monthly precipitation (mm) during the experiment period, from April 2011 to April 2012. Data obtained from Posto Agrometeorológico LEB, Escola Superior de Agricultura "Luiz de Queiroz", Piracicaba, SP, Brazil. 
de 1.266 indivíduos ha-1 (indivíduos com DAP a partir de $10 \mathrm{~cm}$ ) (Castanho 2009).

Em uma Floresta Estacional Semidecidual ribeirinha com influência fluvial permanente que seria desmatada, foram coletados 30 indivíduos da espécie de epífita Aechmea bromeliifolia (Rudge) Baker (Bromeliaceae). Essa floresta se encontrava no município de Santa Bárbara D'Oeste-SP, também apresentando clima do tipo Cwa, de acordo com Köppen (Setzer 1966) e condições climáticas semelhantes às daquela descrita acima. Os indivíduos de epífitas coletados foram identificados por comparações no herbário ESA, separados de sua touceira, fotografados e caracterizados a partir do tamanho, massa fresca e número de brotos. Posteriormente, foram divididos em três grupos de acordo com sua massa fresca, a saber: 1. Pequeno porte - 12 indivíduos com massa fresca entre 8,7 e 78,8 g; 2. Médio porte: 12 indivíduos com massa fresca entre 105,5 e 239,4 g; 3 . Grande porte: 6 indivíduos com massa fresca entre 250,1 e 949,2 g.

Cada grupo de bromélias teve seus indivíduos igualmente distribuídos, de maneira aleatória, entre 30 forófitos de seis diferentes espécies, na área de estudo, onde havia sido previamente realizado levantamento florístico e fitossociológico (Castanho 2009). Essas espécies se diferenciavam de acordo com fenologia de perda foliar e rugosidade de casca (tabela 1).

As bromélias foram amarradas pelo rizoma e pelas folhas a troncos verticais dos forófitos, a aproximadamente 2 a 2,5 $\mathrm{m}$ de altura, utilizando-se barbante de sisal (figura 2). Esse transplante foi realizado em abril de 2011.

No decorrer do experimento, houve a morte de um indivíduo de Cordia ecalyculata e, consequentemente, da epífita sobre ele. Isso deixou os dados desbalanceados, porém não impossibilitou sua análise.

Entre junho de 2011 e abril de 2012, a área foi mensalmente visitada e a cobertura de dossel sobre cada um dos 30 forófitos escolhidos foi medida, usando-se um densiômetro esférico côncavo da marca Forest Densiometers, Modelo-C (Lemmon 1957). Essa medida foi feita para se confirmarem as classificações de deciduidade das árvores, dadas pela literatura. Além disso, ela serviria para computar também o efeito da cobertura de árvores vizinhas do forófito sobre cada ponto amostral. Foram tiradas as médias entre os diferentes meses para se estabelecer a cobertura de dossel anual sobre cada ponto do experimento. Para as análises, houve transformação em arco-seno desses dados, por serem percentuais (Zar 1974).
Em abril de 2012, epífitas foram observadas e elas foram caracterizadas em sobreviventes (com meristemas funcionais, capazes de se desenvolver) ou mortas (sem mostrar qualquer possibilidade de se desenvolver ou gerar descendentes). Também foi contado o número de brotos novos que cada uma delas havia emitido desde o transplante, como medida do desenvolvimento dessas bromélias.

Para analisar a sobrevivência das epífitas em função de seus grupos de tamanho, das espécies de forófitos e da rugosidade de tronco, foram feitas tabelas de contingência e a independência entre suas células foi verificada pelo teste Qui-quadrado, havendo correção de Yates quando necessário. Quando o resultado se mostrou significativo, tabelas de contingência foram desmembradas e suas células analisadas duas a duas pelo teste Qui-quadrado. A relação entre sobrevivência e média anual de cobertura de dossel foi analisada por regressão logística.

Foi realizada uma análise de variância (ANOVA) de dois fatores para se avaliar se o grupo em que as epífitas se encontravam ou as espécies de forófitos influenciaram o número de brotos emitidos. Médias de brotamento foram posteriormente comparadas pelo teste de Tukey. Também foi realizada ANOVA para avaliar se o brotamento das bromélias foi influenciado pela rugosidade de tronco do forófito. Para analisar se essa mesma variável foi influenciada pela média anual de cobertura de dossel, foi feita análise de correlação, utilizando-se coeficiente de correlação de Spearman.

As análises foram embasadas em Gotelli \& Ellison (2012) e realizadas no software R (R Development Core Team 2011).

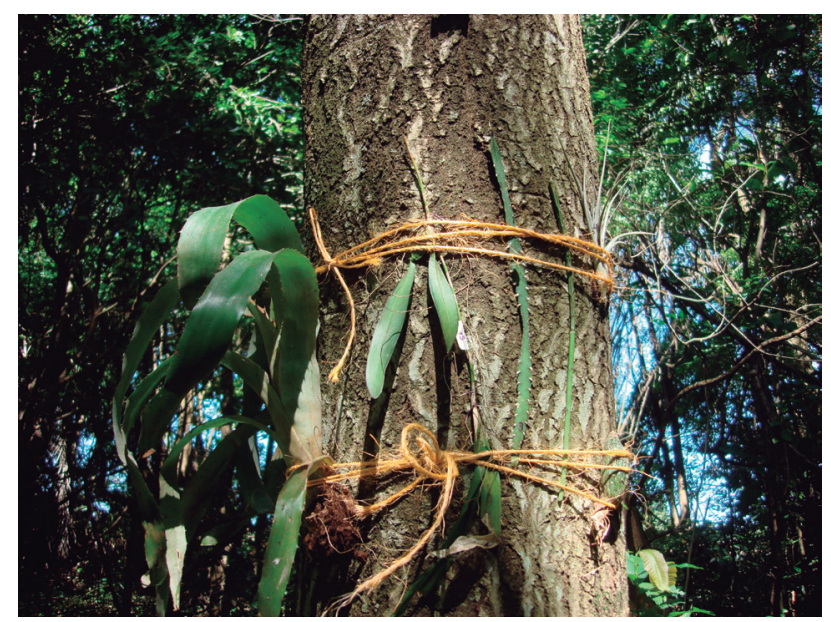

Figura 2: Transplante de epífitas a tronco de forófito. Iracemápolis, SP, Brasil.

Figure 2: Epiphytes transplanted to phorophyte's trunk. Iracemápolis, SP, Brazil. 
Tabela 1. Espécies de árvores escolhidas para o transplante de epífitas em Floresta Estacional Semidecidual em restauração há 23 anos, em Iracemápolis, SP, Brasil, 2011. Referências: (1) Lorenzi (1992); (2) Morellato (1991).

Table 1. Tree species used for transplatations of epiphytes, in a 23-year-old Semideciduous Seasonal Forest in process of restoration, in Iracemápolis, SP, Brazil. References: (1) Lorenzi (1992); (2) Morellato (1991).

\begin{tabular}{llcc}
\hline Família & Espécies de forófitos & Deciduidade & Rugosidade \\
\hline Boraginaceae & Cordia ecalyculata Vell. & Perenifólia $^{2}$ & Rugosa \\
Lauraceae & Nectandra megapotamica (Spreng.) Mez & Perenifólia $^{1}$ & Lisa \\
Rutaceae & Balfourodendron riedelianum (Engl.) Engl. & Semidecídua $^{1}$ & Lisa \\
Lythraceae & Lafoensia glyptocarpa Koehne & Semidecídua $^{1}$ & Rugosa \\
Lecythidaceae & Cariniana estrellensis (Raddi) Kuntze & Decídua $^{2}$ & Rugosa \\
Fabaceae & Centrolobium tomentosum Guillem. ex Benth. & Decídua $^{2}$ & Lisa \\
\hline
\end{tabular}

\section{Resultados}

Considerando todos os indivíduos transplantados, a sobrevivência média foi de $75,9 \%$ e a brotação foi de 0,79 brotos por indivíduo. As taxas de sobrevivência e de emissão de brotos de cada classe de massa fresca das bromélias são mostradas na tabela 2 .

A sobrevivência dos indivíduos de $A$. bromeliifolia variou significativamente de acordo com os grupos de diferentes massas frescas das epífitas $\left(\chi^{2}=8,066\right.$; g.l. $=2 ; \mathrm{P}=0,018)$. Ela, contudo, não respondeu de forma significativa às médias anuais de cobertura de dossel $(\mathrm{z}=-0,832 ;$ g.l. $=27 ; \mathrm{P}=0,405)$, à rugosidade do tronco $\left(\chi^{2}=0,011 ;\right.$ g.l. $\left.=1 ; \mathrm{P}=0,917\right)$ ou à espécie de forófito $\left(\chi^{2}=2,787 ;\right.$ g.1. $\left.=5 ; \mathrm{P}=0,733\right)$.

De mesma forma, a emissão de brotos da bromélia respondeu de forma significativa às suas diferentes classes de massa fresca $(\mathrm{F}=6,107 ;$ g.l. $=2 ; \mathrm{P}=0,008)$. Não houve resposta significativamente distinta de acordo com as médias anuais de cobertura de dossel das árvores (rho $=0,1296 ; \mathrm{P}=0,503)$, com sua rugosidade de casca $(\mathrm{F}=0,0035 ;$ g.l. $=1 ; \mathrm{P}=0,953)$ ou com a espécie do forófito $(\mathrm{F}=0,2291$; g.l. $=5$; $\mathrm{P}=0,946)$.

\section{Discussão}

As espécies de forófitos, então com cerca de 23 anos, bem como a rugosidade de suas cascas e suas fenologias de perda foliar, não foram capazes de influenciar significativamente a sobrevivência e nem o brotamento das epífitas analisadas. Árvores podem apresentar grandes diferenças entre indivíduos de mesma espécie, impedindo que ela demonstre padrões homogêneos (Hubbell 2005). Isso dificulta que haja preferência de uma espécie de epífita por determinada espécie de forófito. Além disso, indivíduos arbóreos podem sofrer grandes mudanças em suas características ao longo do amadurecimento, oferecendo diferentes condições a epífitas com o passar do tempo (Benzing 2004). Por exemplo, a rugosidade da superfície de tronco de uma espécie pode aumentar com a idade da árvore (Torres et al. 1994). A floresta alvo do enriquecimento neste trabalho tinha 23 anos. Uma hipótese que pode ser apresentada é a de que essa idade pode não ter sido suficiente para padrões de forófitos se tornarem fortes o bastante para se influenciar o desenvolvimento das epífitas sobre eles. Outra hipótese é a de que, mesmo tendo sido utilizadas seis espécies de forófitos, que mostravam distintas rugosidades de casca e médias anuais de cobertura de dossel entre 79,3\% e 92,9\%, as epífitas simplesmente não apresentaram respostas a essa amplitude de características. Ainda há a hipótese de que, na natureza, a eventual seleção de forófitos por essa espécie de epífita ocorra na fase de germinação das sementes e no subsequente estabelecimento das plântulas, e não na fixação de plantas maiores transplantadas. Por fim, essa espécie de epífita pode simplesmente não ser seletiva, não apresentando preferências ou restrições a forófitos, crescendo igualmente sobre qualquer um dos estudados.

Todavia, vale sublinhar que os resultados obtidos com essa espécie de bromélia sugerem que, eventualmente, as características das epífitas a serem transplantadas podem ser mais importantes do que aquelas das árvores hospedeiras.

A massa que as bromélias apresentavam no momento de seu transplante foi um fator importante em sua sobrevivência e desenvolvimento no período de um ano. Em estudos envolvendo transplantes de epífitas em florestas, Jasper et al. (2005) concluíram que aquelas transplantadas mais jovens apresentavam maiores chances de sobrevivência. Benzing (2005) sugere que há uma relação inversa entre tamanho e taxa de crescimento em organismos epifíticos. 
Tabela 2. Sobrevivência e brotamento de indivíduos de A. bromeliifolia, um ano após seu transplante, entre abril de 2011 e abril de 2012 , em Iracemápolis-SP. Letras sobrescritas iguais: não diferem entre si pelo teste de Tukey ou pelo teste Qui-quadrado.

Table 2. Survival and sprouting rates of individuals of A. bromeliifolia, one year after transplantations, from April 2011 to April 2012, Iracemápolis-SP, Brazil. Equal superscript letters: Do not differ from each other, according to Tukey or Chi-Squared tests.

\begin{tabular}{clll}
\hline Grupo & Massa inicial $(\mathrm{g})$ & Sobrevivência $(\%)$ & Brotos/indivíduo \\
\hline 1 & $8,7-78,8$ & $50,0^{\mathrm{b}}$ & $0,33^{\mathrm{b}}$ \\
2 & $105,5-239,4$ & $100,0^{\mathrm{a}}$ & $1,36^{\mathrm{a}}$ \\
3 & $250,1-949,2$ & $83,3^{\mathrm{ab}}$ & $0,67^{\mathrm{ab}}$ \\
& & $\left(x^{2}=8,066 ;\right.$ g.l. $\left.=2 ; \mathrm{P}=0,0177\right)$ & $(\mathrm{F}=6,107 ; \mathrm{g} .1 . \mathrm{l}=2, \mathrm{P}=0,008)$ \\
\hline
\end{tabular}

Contudo, o que foi evidenciado foi que as epífitas pertencentes à classe inferior de massa fresca apresentaram tanto sobrevivência quanto brotação inferiores àquelas de peso intermediário. Os indivíduos menores não foram capazes de resistir ao estresse do transplante e sobreviver até alcançarem maturidade para se propagarem vegetativamente e garantir sua permanência no ambiente. Assim, deve haver um tamanho ótimo de epífitas a serem transplantadas em florestas, de modo que sejam capazes de resistir ao estresse da mudança de habitat e, ao mesmo tempo, dar continuidade a seu desenvolvimento no novo ambiente. De fato, neste trabalho, os indivíduos de médio porte puderam sobreviver e emitir brotos, o que nos sugere que seja uma melhor opção investir esforços de transplantes futuros de A. bromeliifolia principalmente em indivíduos de massa fresca entre 105 e $240 \mathrm{~g}$.

O transplante de indivíduos maiores e mais maduros também pode ser importante para áreas em restauração, já que, quando transplantados, eles podem entrar mais rapidamente em fase reprodutiva, fornecendo diásporos à floresta (Jasper et al. 2005). Neste trabalho, o transplante de indivíduos de maior porte teve sucesso em valores intermediários, não se diferindo significativamente nem dos indivíduos de menor e nem dos de médio porte. Assim, para esta espécie, pode ser recomendável que se insiram, em uma floresta em processo de restauração, indivíduos mais maduros, a fim de que eles floresçam e frutifiquem mais cedo, fornecendo recursos ao novo ambiente. Contudo, o maior esforço do transplante não deve ser voltado apenas aos de maior porte. Isso porque, por apresentarem maior massa, seu transporte e manuseio são mais difíceis. Os indivíduos de peso intermediário apresentaram taxas de sobrevivência e propagação vegetativa mais satisfatórias, além de apresentarem melhores condições logísticas de transplante. Assim, o enriquecimento de florestas com novas formas de vida deveria ser mais concentrado neles.
Vale ressaltar que não se está propondo, aqui, que indivíduos de pequeno ou grande porte de epífitas devam ser descartados, especialmente se forem os únicos disponíveis. Apenas se sugere que, para A. bromeliifolia, os indivíduos de médio porte seriam a opção mais recomendada para o transplante, se houvesse uma necessidade de escolha entre diversos indivíduos disponíveis. Também se sugere que novos estudos sejam feitos com outras espécies, a fim de mostrar se esse padrão se repete entre epífitas.

\section{Agradecimentos}

Agradecemos enormemente à Fundação de Amparo à Pesquisa do Estado de São Paulo (FAPESP), pelo apoio ao projeto por meio do processo 2010/04370-9. Agradecemos também ao CNPq pelos recursos destinados ao Laboratório de Ecologia e Restauração Florestal, por meio de projeto temático, processo 561897/2010-7.

\section{Literatura citada}

Addo-Fordjour, P., Anning, A.K., Addo, M.G. \& Osei, M.F. 2009. Composition and distribution of vascular epiphytes in a tropical semideciduos forest, Ghana. African Journal of Ecology 47: 767-773.

Bellotto, A., Viani, R.A.G., Gandolfi, S. \& Rodrigues, R.R. 2009. Inserção de outras formas de vida no processo de restauração. In: R.R. Rodrigues, P.H.S. Brancalion \& I. Isernhagen (orgs.). Pacto para a restauração ecológica da Mata Atlântica: referencial dos conceitos e ações de restauração florestal. Instituto BioAtlântica, São Paulo, cap. 1: fase 6, pp. 55-61.

Benavides, A.M., Vasco, A., Duque, A.J. \& Duivenvoorden, J.F. 2011. Association of vascular epiphytes with landscape units and phorophytes in humid lowland forests of Colombian Amazonia. Journal of Tropical Ecology 27: 223-237.

Benzing, D.H. 2004. Vascular epiphytes. In: M. Lowman, B. Rinker (eds.). Forest canopies. 2ed. Elsevier, Boston, pp. 175-211. 
Bonnet, A., Curcio, G.R., Lavoranti, O.J. \& Galvão, F. 2010. Relações de epífitos vasculares com fatores ambientais nas florestas do Rio Tibagi, Paraná, Brasil. Biotemas 23: 37-47.

Brasil. 2012. Lei n. 12651, de 25 de maio de 2012. Dispõe sobre a proteção da vegetação nativa; altera as Leis $\mathrm{n}^{\circ} \mathrm{s} 6.938$, de 31 de agosto de 1981, 9.393, de 19 de dezembro de 1996, e 11.428 , de 22 de dezembro de 2006; revoga as Leis $n^{\circ} \mathrm{S} 4.771$, de 15 de setembro de 1965 , e 7.754 , de 14 de abril de 1989, e a Medida Provisória $\mathrm{n}^{\circ}$ 2.166-67, de 24 de agosto de 2001; e dá outras providências. Diário Oficial, Brasília, 28 maio 2012. Seção 1, p. 1-16.

Breier, T.B. 2005. Epifitismo vascular em florestas do sudeste do Brasil. Tese de doutorado, Universidade Estadual de Campinas, Campinas.

Cain, M.L., Milligan, B.G. \& Strand, A.E. 2000. Longdistance seed dispersal in plant populations. American Journal of Botany 87: 1217-1227.

Callaway, R.M., Reinhart, K.O., Moore, G.W., Moore, D.J. \& Pennings, S.C. 2002. Epiphyte host preferences and host traits: mechanisms for species-specific interactions. Oecologia, Berlin 132: 221-230.

Carvalhaes, M.A., Cunha; G.C., Gusson, E., Vidal, C.Y. \& Gandara, F.B.M. 2007. Incorporação de bromélias epífitas no processo de restauração de áreas degradadas na Mata Atlântica - um estudo em Registro, SP. In: Resumos $58^{\circ}$ Congresso Nacional de Botânica, São Paulo, pp. 214.

Cascante-Marín, A., Meijenfeldt, N., von Leeuw, H.M.H., Wolf, J.H.D., Oostermeijer, J.G.B. \& den Nijs, J.C.M. 2009. Dispersal limitation in epiphytic bromeliad communities in a Costa Rican fragmented montane landscape. Journal of Tropical Ecology 25: 63-73.

Castanho, G.G. 2009. Avaliação de dois trechos de uma Floresta Estacional Semidecidual restaurada por meio de plantio, com 18 a 20 anos, no Sudeste do Brasil. Dissertação de Mestrado, Escola Superior de Agricultura "Luiz de Queiroz", Universidade de São Paulo, Piracicaba.

CEPAGRI - Centro de Pesquisas Meteorológicas e Climáticas Aplicadas à Agricultura. 2012. Climas dos municípios paulistas. http://www.cpa.unicamp.br/ outras-informacoes/clima_muni_248.html (acesso em 19.12.2012).

Cestari, C. 2009. Epiphyte plants use by birds in Brazil. Oecologia Brasiliensis 13: 689-712.

Dorneles, L.T. \& Trevelin, V. 2011. Aclimatização e reintrodução de Cattleya intermedia Graham ex Hook (Orchidaceae) obtidas por propagação in vitro. Iheringia, série Botânica 66: 167-174.
Duarte, M.M. 2013. Transplante de epífitas entre Florestas Estacionais Semideciduais para enriquecimento de florestas em processo de restauração. Dissertação de Mestrado, Escola Superior de Agricultura "Luiz de Queiroz", Universidade de São Paulo, Piracicaba.

Durigan, G., Engel, V.L., Torezan, J.M., Melo, A.C.G., Marques, M.C.M., Martins, S.V., Reis, A. \& Scarano, F.R. 2010. Normas jurídicas para a restauração ecológica: uma barreira a mais a dificultar o êxito das iniciativas? Revista Árvore 34: 471-485.

Fayle, T.M., Chung, A.Y.C., Dumbrell, A.J., Eggleton, P. \& Foster, W.A. 2009. The effect of rain forest canopy architecture on the distribution of epiphytic ferns (Asplenium spp.) in Sabah, Malaysia. Biotropica 41: 676-681.

Font Quer, P.1953. Diccionario de Botánica. Editorial Labor, Barcelona.

FAO. 2011. State of the world's forests. Food and Agriculture Organization, Roma.

Garcia, L.C., Hobbs, R.J., Ribeiro, D.B., Tamashiro, J.Y., Santos, F.A.M. \& Rodrigues, R.R. 2011. Changes in vegetation along restoration time: Influence of composition and diversity of planted trees on natural regeneration. In: Book of abstracts of the $4^{\text {th }}$ World Conference on Ecological Restoration, Mérida, pp. 81-82.

Gentry, A.H. \& Dodson, C. 1987. Diversity and biogeography of neotropical vascular epiphytes. Annals of the Missouri Botanical Garden 74: 205-233.

Gotelli, N.J. \& Ellison, A.M. 2011. Princípios de estatística em ecologia. Artmed, Porto Alegre.

Hubbell, S.P. 2005. Neutral theory in community ecology and the hypothesis of functional equivalence. Functional Ecology 19: 166-172.

Jakovac, A.C.C., Vosqueritchian, S.B. \& Basso, F.A. 2007. Epiphytes transplant to improve the diversity on restored areas. In: Annales del II Simposio Internacional sobre Restauración Ecológica, Santa Clara, resumo, pp. 207.

Jasper, A., Freitas, E. M., Musskopf, E.L. \& Bruxel, J. 2005. Metodologia de salvamento de Bromeliaceae, Cactaceae e Orchidaceae na pequena central hidrelétrica (PCH) Salto Forqueta - São José do Herval/Putinga-RSBrasil. Pesquisas, Botânica 56: 265-284.

Kersten, R.A. \& Kuniyoshi, Y.S. 2009. Conservação das florestas na bacia do Alto Iguaçu, Paraná - Avaliação da comunidade de epífitas vasculares em diferentes estágios serais. Floresta 39: 51-66.

Lemmon, P.E. 1957. A new instrument for measuring forest overstory density. Journal of Forestry 55: 667-669.

Lorenzi, H. 1992. Árvores brasileiras: manual de identificação e cultivo de plantas arbóreas do Brasil. v.1. Instituto Plantarum, Nova Odessa. 
Morellato, L.P.C. 1991. Fenologia de árvores, arbustos e lianas em uma floresta semidecídua no sudeste do Brasil. Tese de doutorado, Universidade Estadual de Campinas, Campinas.

Nadkarni, N.M. \& Solano, R. 2002. Potential effects of climate change on canopy communities in a tropical cloud forest: an experimental approach. Oecologia 131: 580-586.

Nadkarni, N.M. Schaefer, D., Matelson, T.J. \& Solano, R. 2004. Biomass and nutrient pools of canopy and terrestrial components in a primary and a secondary montane cloud forest, Costa Rica. Forest Ecology and Management 198: 223-236.

Nievola, C.C. \& Tamaki, V. 2009. O resgate de plantas no trecho sul do Rodoanel Mário Covas. In: Anais do $3^{\circ}$ Simpósio sobre Recuperação de Áreas Degradadas, São Paulo, pp. 55-60.

Obermüller, F.A., Silveira, M., Salimon, C.I., Daly, D.C. 2012. Epiphytic (including hemiepiphytes) diversity in three timber species in the southwestern Amazon, Brazil. Biodiversity and Conservation 21: 565-575.

Oliveira, R.R. 2004. Importância das bromélias epífitas na ciclagem de nutrientes da Floresta Atlântica. Acta Botanica Brasilica 18: 793-799.

Otero, J.T., Aragón, S. \& Ackerman, J.D. 2007. Site variation in spatial aggregation and phorophyte preference in Psychilis monensis (Orchidaceae). Biotropica 39: 227-231.

Pett-Ridge, J. \& Silver, W.L. 2002. Survival, growth, and ecosystem dynamics of displaced bromeliads in a Montane Tropical Forest. Biotropica 34: 211-224.
R Development Core team. 2011. R: A language and environment for statistical computing. http://www.Rproject.org/ (acesso em 05.09.2012).

Rodrigues, R.R., Leitão Filho, H.F. \& Crestana, M.S.M. 1992. Regeneração do entorno da represa de abastecimento de água do município de Iracemápolis/ SP. In: Anais do Simpósio Nacional de Recuperação de Áreas Degradadas, Curitiba, pp. 406-416.

Rodrigues, R.R., Lima, R.A.F., Gandolfi, S. \& Nave, A.G. 2009. On the restoration of high diversity forests: 30 years of experience in the Brazilian Atlantic Forest. Biological Conservation 142: 1242-1251.

Setzer, J. 1966. Atlas climático e ecológico do Estado de São Paulo. Comissão Interestadual da Bacia do ParanáUruguai e Centrais Elétricas do Estado de São Paulo, São Paulo.

Scheffknecht, S., Hülber, K., Mata-Rosas, M. \& Hietz P. 2010. Seedling establishment of epiphytic orchids in forests and coffee plantations in Central Veracruz, Mexico. Journal of Tropical Ecology 26: 93-102.

Torres, R.B., Kinoshita, L.S. \& Martins, F.R. 1994. Aplicação de padrões de casca na identificação de árvores da Estação Ecológica de Angatuba, SP. Revista Brasileira de Botânica 17: 119-127.

Zar, J.H. 1974. Biostatistical analysis. Prentice Hall, Englewood Cliffs.

Zotz, G. \& Vollrath, B. 2002. Substrate preferences of epiphytic bromeliads: an experimental approach. Acta Oecologica 23: 99-102. 